\title{
1 Seasonal hydrologic buffer on continents: patterns, drivers and ecological 2 benefits
}

3

4 Sylvain Kuppel ${ }^{\mathrm{a}, 1, *}$, Ying Fan ${ }^{\mathrm{b}}$, and Esteban G. Jobbágy ${ }^{\mathrm{a}}$

5

$6{ }^{\text {a }}$ Grupo de Estudios Ambientales, IMASL - CONICET \& Universidad Nacional de San Luis, 7 Avenida Italia 1556, D5700HHW San Luis, Argentina

8 bepartment of Earth and Planetary Sciences, Rutgers University, Wright Laboratories, 610

9 Taylor Road, Piscataway, NJ 08854-8066, USA

10

$11 *$ Corresponding author

12 E-mail addresses: sylvain.kuppel@abdn.ac.uk (S. Kuppel), yingfan@eps.rutgers.edu (Y. Fan), 13 jobbagy@gmail.com (E.G. Jobbágy).

14

\section{Keywords}

16 seasonal water storage, hydrologic buffer, lateral water transfer, delayed evaporation, climatic 17 water imbalance, snow storage

\footnotetext{
${ }^{1}$ Present address: Northern Rivers Institute, School of Geosciences, University of Aberdeen, Aberdeen, AB24 3UF, Scotland, UK
} 


\section{Abstract}

20 Continental precipitation returns to the atmosphere and the ocean with a delay that is critical in 21 regulating seasonal water supply to ecosystems and societies. We quantify the magnitude and 22 spatial patterns of this seasonal hydrologic buffer, its climatic and terrain drivers, and its apparent benefits to ecosystems using observed precipitation, climate reanalysis evaporation, GRACE seasonal water storage change, and MODIS vegetation index for a $1^{\circ} \times 1^{\circ}$ global grid. We found that (1) seasonal hydrologic buffering is widespread and averages $241 \mathrm{~mm} \cdot \mathrm{yr}^{-1}$ on land (a quarter of continental precipitation); it supports evaporation 3-to-9 months of the year over all regions except the per-humid tropics and energy limited high latitudes, (2) the seasonal climatic water imbalance, with surplus in some months and deficit in others, drives hydrologic buffering in lower latitudes, while it is controlled by snow/ice storage in high latitudes, (3) the main terrain effect at our scale of analysis is grid-to-grid water transfer via large rivers providing lateral subsidy to lowland basins, and (4) buffering is manifested in global patterns of plant water use, as shown by high evaporation levels in water deficit conditions, particularly under tropical monsoonal climate. Our results highlight the paramount role of seasonal land water storage and redistribution in supporting ecosystem productivity, and provide a reference to understanding likely impacts of global change on the water cycle and ecosystem dynamics in the future.

\section{Introduction}

Precipitation (P) falling on land is temporarily stored in snow packs, soils, groundwater, rivers, lakes and wetlands. This storage and its delayed release regulate the timing of the global water cycle, so that water availability to land ecosystems and societies is partially decoupled from precipitation, as evidenced by flowing rivers and thriving vegetation in the absence of $\mathrm{P}$. This storage and release occur over a range of time scales (hours to millennia) and regulates a range of processes (flooding [1] to long-term carbon cycle through weathering [2]). In this study we focus on the seasonal time scale which is critical to understanding vegetation activity and water supply to human needs and has a growing body of available global data. In the remainder of this paper we will refer to this seasonal storage and release as the "seasonal hydrologic buffer" (SHB). Knowing where, how much, for how long, and why precipitation is held on land through 
49 the course of a growing season will give clues to where on Earth the service (both for nature and 50 humans) of seasonal hydrological buffering is most significant, how it is controlled by regional environmental conditions, and to what extent it may be affected by global environmental change.

At a given location and in a given month, how much of the water storage is recharged or depleted depends on several fluxes, broadly grouped here into climatically-driven vertical fluxes and terrain driven lateral fluxes. Of the former, an example is found in strongly seasonal climates where the wet-season surplus ( $P>E, E=e v a p o r a t i o n)$ is carried over to fill the dry-season deficit $(\mathrm{P}<\mathrm{E})$ in a tropical monsoonal or Mediterranean climate, as emphasized at least since Thornthwaite's seasonal diagrams of climatic water imbalance [3]. Another climatic factor is snow and ice in cold regions where winter $\mathrm{P}$ is held until the melt season. Of the terrain-driven fluxes, those operating at hourly to daily scales, such as rapid runoff to local streams, are less important for seasonal hydrological buffering, but regional-scale lateral transport through large river networks towards floodplains can delay the outflow, holding water that later will be exported to downstream areas or evaporated in-situ. Soil storage capacity is another terrain driver, which can either restrict buffering where the bedrock is close to the surface or enhance it where soils and plant roots are deep and/or groundwater is an important source - through phreatophytic vegetation or groundwater-fed irrigation. Lastly, lakes and reservoirs offer an additional land storage mechanism.

We ask the following questions (1) What is the magnitude and geographic distribution of seasonal water buffering? (2) What are the drivers of such storage and release? Where on Earth are climate or the terrain the primary drivers of seasonal water buffering? (3) How does this seasonal storage correlates with geographic and seasonal patterns of plant productivity? These questions will shed light on where and how seasonal hydrologic buffering allows terrestrial life to escape strict dependence on current and local precipitation, how human activities may alter natural buffering, and how they could be steered to maximize ecological and social benefits. We will address these questions through a set of global data analyses over $1^{\circ} \times 1^{\circ}$ grids and at monthly steps over the 2003-2010 period.

\section{Materials and methods}


81 Over a given grid, the monthly water budget can be written as:

$$
\frac{\Delta S}{\Delta t}=P-E-Q
$$

82 where $\Delta \mathrm{S}$ is the change in terrestrial water storage (hereafter $\mathrm{S}$ ) over the monthly timespan $\Delta \mathrm{t}, \mathrm{P}$ 83 is monthly precipitation and E monthly evaporation from the grid, and Q is the lateral, grid to 84 grid transport (run-on or runoff).

85

\subsection{Data sources}

The storage change is estimated from GRACE (the Gravity Recovery And Climate Experiment) satellites [4], which have enabled independent constrains on the storage term over global grids [5,6] from April 2002 onwards. Starting from 2003 (first full calendar year covered), here we combined the three RL05 solutions releases of the $1 \times 1^{\circ}$ near-monthly product provided by the Center for Space Research at the University of Texas at Austin (CSR), the Jet Propulsion Laboratory (JPL), and the German Research Centre for Geosciences (GFZ). After applying the scaling factor (provided along with the data sets) to compensate for signal alteration from sampling and post-processing of the original data [6], we averaged the three data sources to derive a mean TWS record, as this approach allows reducing the noise within the available gravity field solutions [7]. A quality criterion for the $\mathrm{S}$ record is defined as $q_{\mathrm{S}}>1$, with

$$
q_{S}=\frac{A_{S}}{2 \cdot e_{S}}
$$

where $\mathrm{A}_{\mathrm{S}}$ is the mean seasonal amplitude of $\mathrm{S}$ over one year, and $e_{\mathrm{S}}$ is the time-invariant error associated to the GRACE record, which bears two uncorrelated components:

$$
\mathrm{e}_{\mathrm{S}}=\sqrt{\mathrm{e}_{\mathrm{S}, \mathrm{meas}}^{2}+\mathrm{e}_{\mathrm{S}, \mathrm{leak}}^{2}},
$$

where $e_{\mathrm{S} \text {,meas }}$ is the measurement error and $e_{\mathrm{S} \text {,leak }}$ is the leakage error arising from data filtering and rescaling from the original surface mass variations measured by GRACE [6]. Like all seasonal metrics used in this study, $A_{S}$ is calculated for each 12-month moving window of the study period (85 overlapping annual cycles over 2003-2010), and then time-averaged, to best use the seasonal content in the data. 
P, snowfall, and E products are from ECMWF-Interim reanalysis: $\mathrm{P}$ and snowfall have been corrected for biases using GPCP gauge-satellite observations (ERA-Interim/LAND, [8]), while $\mathrm{E}$ is taken from the ERA-Interim reanalysis [9] which assimilates atmospheric observations with energy and water budget closures in the atmosphere (vs. land model estimates which are poorly constrained [10]). P and snowfall are available to 2010, setting our study period as 2003-2010. We also use potential evaporation $\left(E_{p}\right)$ from the CRU TS3.23 monthly database, based on a modified version of the Penman-Monteith equation [11].

113

The Enhanced Vegetation Index (EVI) is based on the level-3 MODIS composite NDVI available at monthly, $0.05 \times 0.05^{\circ}$ resolution (MOD13C2, collection 5) [12]. Terrain slope was calculated using the elevation product of the Shuttle Radar Topography Mission (SRTM) [13] at 3 -arc-seconds ( $\sim 90$ meters) resolution, then using the mean and maximum values for the $1 \times 1^{\circ}$ resolution of this study. Finally, the land cover classification is provided by the Climate Change Initiative of the European Space Agency (ESA-CCI) 300-m land cover product over the 20052008 period [14], aggregated to $1^{\circ} \times 1^{\circ}$ (Supplementary Fig. S1).

\subsection{Quantifying seasonal hydrologic buffers}

123

expressed at each location as S departures from the 2004-2009 mean baseline. Storage anomalies captured as variations from month to month are precisely what we require to characterize seasonal storage dynamics. We define this observational seasonal hydrologic buffer (SHB) as the filling and releasing of water storage in a grid cell over a season, and we quantify SHB by taking the average between accumulated positive (filling) and negative (releasing) monthly $\mathrm{S}$ variations $(\Delta \mathrm{S} / \Delta \mathrm{t})$ over a 12 -month period:

$$
S H B=\frac{1}{2}\left(\sum \frac{|\Delta S|}{\Delta t}\right)_{1 \text { year }} .
$$

131 In order to compare observed seasonal hydrological buffering with the levels of buffering 132 expected from climatic drivers, we consider the seasonal imbalance between atmospheric supply 133 (P) and demand (potential evaporation, $\mathrm{E}_{\mathrm{p}}$ ), which is referred to as the seasonal hydrologic buffer 
134 resulting from climatic water balance $\left(\mathrm{SHB}_{\mathrm{cwb}}\right)$. It can be estimated from the amplitude and 135 timing of these two variables. Following [15], we estimate $\mathrm{SHB}_{\mathrm{cwb}}$ as the cumulative deficit (sum 136 of $E_{p}-P$ when $E_{p}>P$ ) that can be met by previous water surplus (sum of $P-E_{p}$ when $P>E_{p}$ ):

$$
S H B_{c w b}=\min \left(\int_{P>E_{p}}\left(P-E_{p}\right) d t, \int_{E_{p}>P}\left(E_{p}-P\right) d t\right)_{1 \text { year }},
$$

137 and averaged over the 85 overlapping annual cycles during the study period. For this climatic 138 approach we use $\mathrm{E}_{\mathrm{p}}$ (not $\mathrm{E}$ ) because $\mathrm{E}_{\mathrm{p}}$ is a direct measure of atmospheric water vapor demand 139 independent of vegetation and soil water characteristics.

140 Independently of the seasonal water imbalance characterized above, snow accumulation 141 can enhance seasonal hydrological buffering. We characterized this climatic driver simply 142 based on the continental patterns of mean annual snowfall.

We also account for the contribution of horizontal water transfers to total SHB based on grid-to-grid calculations of lateral transport $\mathrm{Q}$ via the monthly water balance equation 145 (rearranging Eq. 1):

$$
Q=P^{\prime}-E^{\prime}-\frac{\Delta S}{\Delta t},
$$

146 where $\mathrm{P}^{\prime}$ and $\mathrm{E}$ ' are respectively the $\mathrm{P}$ and $\mathrm{E}$ aggregated from daily values to align with 147 GRACE's near-monthly time steps $\Delta \mathrm{t}$, following the methodology of [16]. Separating months 148 with net lateral inflow $(\mathrm{Q}<0)$ and outflow $(\mathrm{Q}>0)$, we derive an idealized, lateral water-balance149 based, seasonal hydrologic buffer, or $\mathrm{SHB}_{\text {lateral: }}$

$$
S H B_{\text {lateral }}=\min \left(\int_{Q<0}|Q| d t, \int_{Q>0} Q d t\right)_{1 \text { year }},
$$

150 where the first term in the parenthesis is the accumulated lateral inflow, and the second term 151 outflow, averaged over the 85 overlapping annual cycles.

Lastly, in order to quantify vegetation benefits from SHB, we record the occurrence of monthly $\mathrm{E}>$ monthly $\mathrm{P}$, where the deficit is thus met by temporal and/or spatial carry-over of water surpluses. We will refer to this as subsidized $E\left(E_{s}\right)$, fed by past and/or upslope surplus. 
156 We examine the magnitude of the subsidized E over a year, calculated as,

$$
E_{S}=\left(\int_{E>P}(E-P) d t\right)_{1 \text { year }} .
$$

157 When $\mathrm{E}>\mathrm{P}$, we further distinguish the relative contribution of the lateral water inflow to $\mathrm{E}_{\mathrm{s}}$

158 (hereafter $\mathrm{E}_{\mathrm{iflw}}$ ). This component is first determined at each location on a monthly basis by

159 comparing the value of runoff $(\mathrm{Q})$ to the monthly subsidized E, distinguishing three cases:

160 - If $Q>0$ : there is net lateral outflow. As a result, the monthly subsidized E must come 161 exclusively from past storage $\left(\Delta S<0\right.$, Eq. (1)), so that $E_{i f l w}=0$.

- If $Q<P-E<0$ : there is net lateral inflow, exceeding subsidized E. All of the latter is

The results are then averaged over all the monthly time steps, providing the fraction of

\section{Results and Discussion}

175 (Question 1) we derived the total seasonal hydrologic buffer (SHB, see Eq. (4) directly from 176 GRACE observations. The global patterns of SHB are shown in Fig. 1, excluding grid cells 177 with low signal-to-noise ratio (i.e., $\mathrm{q}_{\mathrm{S}}<1$ ) and Antarctica and Greenland. The values vary from $178<10 \mathrm{~mm} \cdot \mathrm{yr}^{-1}$ in the Taklimakan desert to $>4,700 \mathrm{~mm} \cdot \mathrm{yr}^{-1}$ (doubling annual P) in the main valley 179 of the Amazon, with $17 \%$ of the land surface displaying values greater than $300 \mathrm{~mm}^{-\mathrm{yr}^{-1}}$. A 180 broad latitudinal distribution is visible, with a narrow band of low SHB values at the equator 181 fringed by higher values in the $5-25^{\circ}$ latitude range. In mid latitudes SHB decreases except in 
182 snow-capped mountains (e.g. Alaskan-Canadian coastal range, Japan, and Kamchatka 183 peninsula) and large river floodplains (e.g. lower Mississippi, Yangzi and Paraná). Integrated

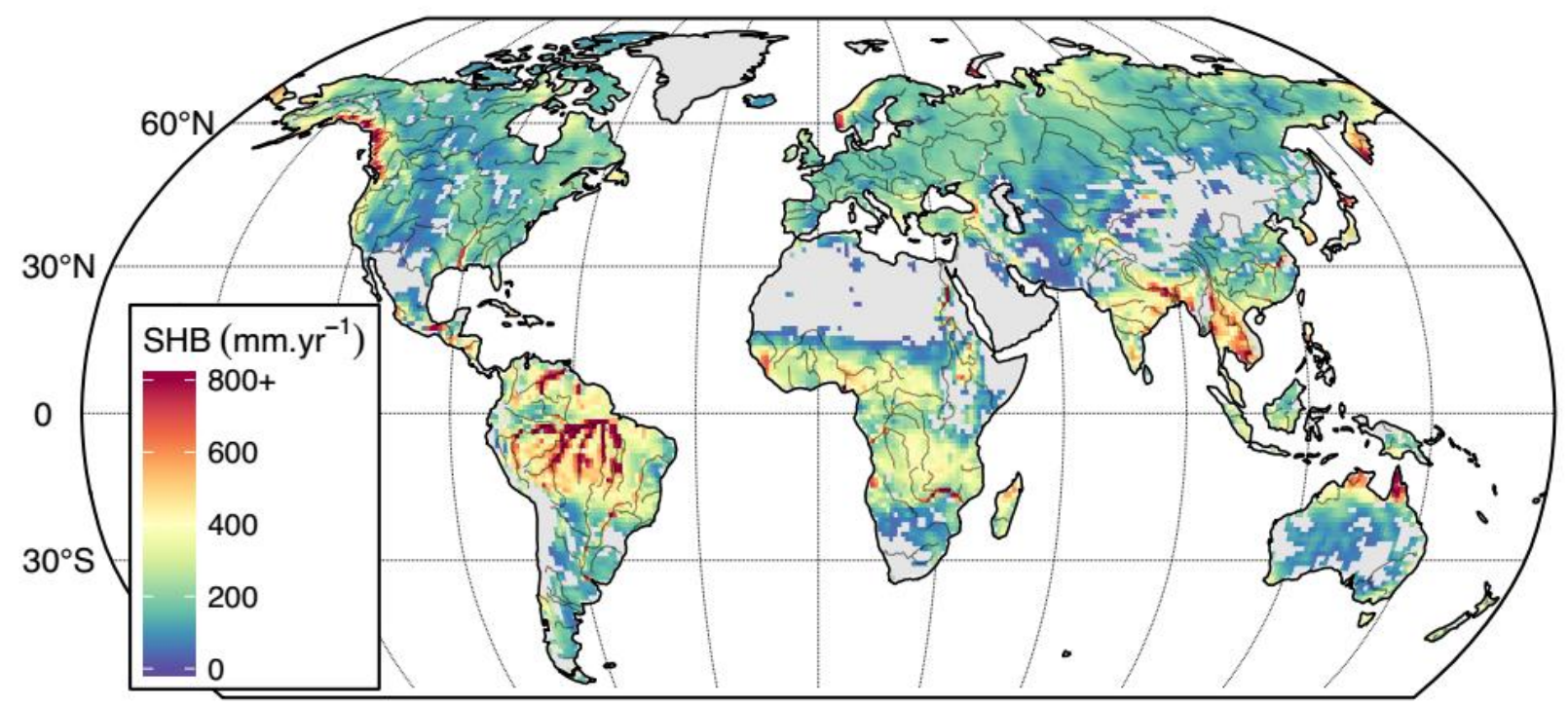

Figure 1. Vertically-integrated seasonal hydrologic buffer (SHB) on land, excluding locations with low signal-to-noise ratio (light grey).

184 globally, this seasonal hydrologic storage is ${ }^{\sim} 22 \times 10^{3} \mathrm{~km}^{3} \cdot \mathrm{yr}^{-1}$ (or $241 \mathrm{~mm} \cdot \mathrm{yr}^{-1}$ as the area-

185 weighted mean water depth), which is about $25 \%$ of the annual $\mathrm{P}$ on land.

186

187

We note that SHB describes a flux and is thus conceptually distinct from a holding capacity, i.e., the "size of the bucket". Taking two idealized examples, qualitatively different systems can display similar SHB values either through a single ample seasonal emptying-

190 refilling sequence or through several smaller non-seasonal sequences, resulting in a

191 comparatively "shallower" storage potential in the second case. In order to evaluate the 192 proportion of water storage variability explained by its annual (i.e. 1-peak seasonal cycle), 193 biannual (i.e. 2-peak seasonal cycle) and higher frequency (i.e. random variability) 194 components, we applied a fast Fourier transform algorithm to S at each location, allowing a 195 variance decomposition into these three harmonics (Fig. 2). We find that although SHB 196 integrates all water storage variations taking place between the annual and monthly scale, in 197 most areas of the world its values are predominantly explained by the annual component of S, 
198 and less by the biannual and higher frequencies. The annual component is most significant in 199 most of the tropics, as well as in regions of Mediterranean climate or snow domination (map in 200 Fig. 2a and typical time series in Supplementary Figs. S2a and S2b). The biannual component 201 is weak except near the equator (Fig. 2b and Supplementary Fig. S2c). Finally, the higher 202 frequency components are significant in regions with low climatic seasonality 

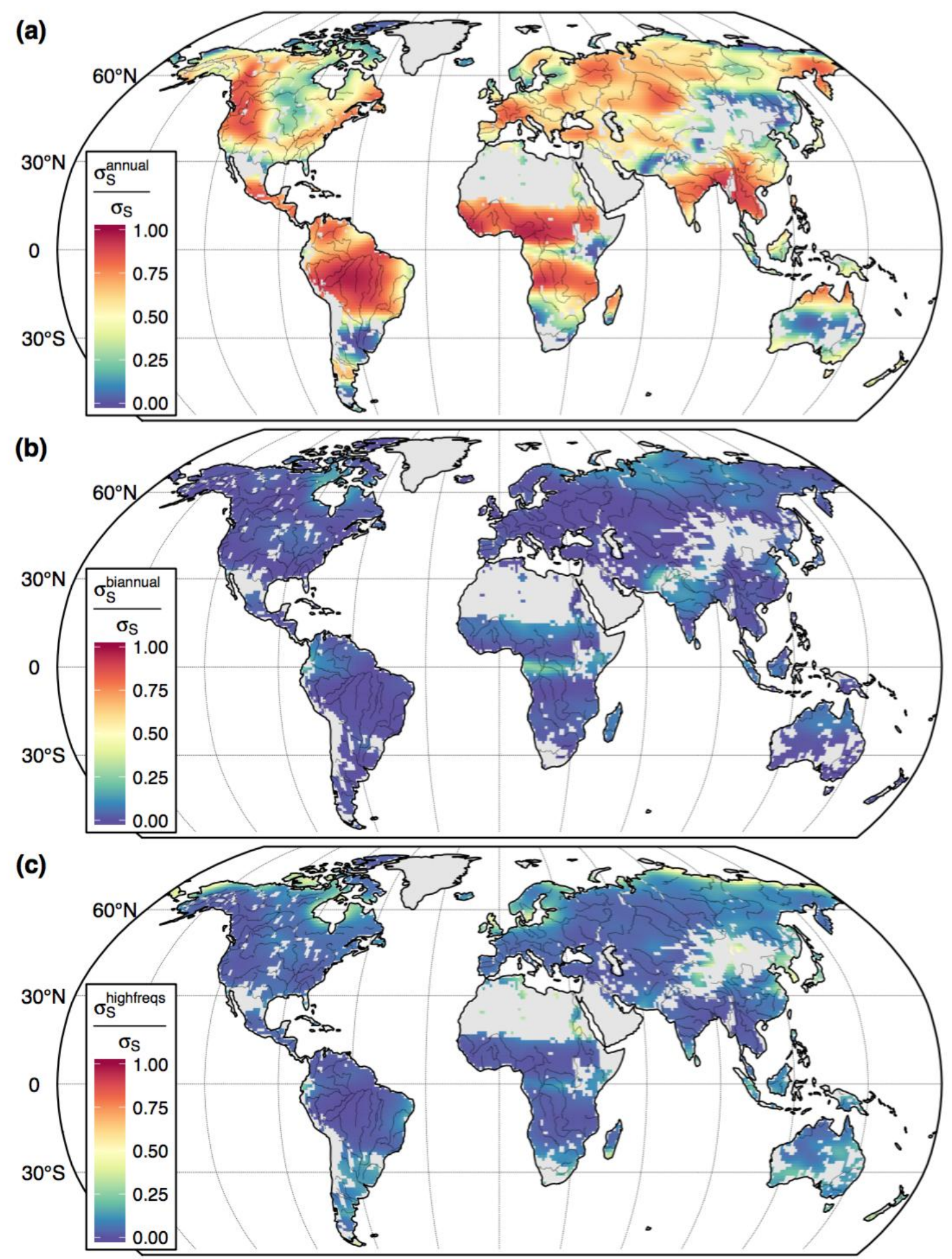

Figure 2. Decomposition of the variance of terrestrial water storage signal $(\Delta S)$ into a) 1-peak seasonal cycle (annual harmonic), b) 2-peaks seasonal cycle (biannual harmonic) and c) higher frequency fluctuations (sum of remaining harmonics). Locations with low signal-to-noise ratio are excluded (light grey). 
204 or where precipitation is low and sporadic (Fig. 2c and Supplementary Fig. S2d). In addition, 205 we use the mean seasonal storage amplitude $\left(A_{\mathrm{s}}\right.$, obtained directly from GRACE) as an 206 estimate of the holding capacity and compare it with SHB, finding that $\mathrm{A}_{\mathrm{S}}$ accounts for at least $20780 \%$ of SHB at more than $86 \%$ of locations considered in this study, with less than $2 \%$ of the 208 pixels showing $\mathrm{A}_{\mathrm{s}} / \mathrm{SHB}$ values lower than 0.6 (not shown).

\subsection{Drivers behind observed storage patterns}

To explore the drivers of SHB and the relative importance of climate and terrain regulating its patterns (Question 2) we developed independent global SHB maps.

213

Seasonal hydrologic buffering resulting from imbalance between $\mathrm{P}$ and $\mathrm{E}_{\mathrm{p}}\left(\mathrm{SHB}_{\mathrm{cwb}}\right.$, Fig. 3a) reveal the climatic inclinations for storing wet-season surplus and releasing it in the deficit periods later. As expected, regions with strongly seasonal climate stand out, corresponding to the large seasonal swings in $\mathrm{P}$ following the annual march of the ITCZ. The highest $\mathrm{SHB}_{\mathrm{cwb}}$ values $\left(500 \mathrm{~mm} \cdot \mathrm{yr}^{-1}\right)$ are found in subtropical regions with winter-dry climate (Köppen-Geiger climate classification, [17]) such as the Sudanian savanna south of the Sahel, the Zambezi region and western Madagascar in Africa, the Indian subcontinent (where $\mathrm{SHB}_{\mathrm{cwb}}$ reaches $810 \mathrm{~mm} . \mathrm{yr}^{-1}$ ), Northern Australia, Eastern Brazil and Venezuela. Zones with high values (300-500 mm.yr ${ }^{-1}$ ) are also found in smaller sectors with Mediterranean climate such as the Pacific coastal regions of the US, central Chile, Peru, and the Mediterranean Sea regions. Also as expected, $\mathrm{SHB}_{\mathrm{cwb}}$ is low in humid equatorial regions (e.g. the western Amazon, Congo, and the Eastern Tropics), and in arid locations (e.g., the Sahara, Gobi and Kalahari deserts, Central US, Saudi Arabia): the former have no demand for seasonal buffering ( $P>\mathrm{E}_{\mathrm{p}}$ every month), and the latter have no means for it ( $\mathrm{P}<\mathrm{E}_{\mathrm{p}}$ every month). About $11 \%$ of the continental surface (excluding Greenland and Antarctica) has $\mathrm{SHB}_{\mathrm{cwb}}$ exceeding $300 \mathrm{~mm} \cdot \mathrm{yr}^{-1}$, with a global volume of $\sim 16 \times 10^{3} \mathrm{~km}^{3} \cdot \mathrm{yr}^{-1}$, or expressed as 230 area-weighted average water depth, $134 \mathrm{~mm} \cdot \mathrm{yr}^{-1}$. Comparing this climatic buffering with 231 GRACE observations (Fig. 3a vs. Fig. 1) and their respective average values (134 vs. 341 mm.yr ${ }^{-}$

$\left.232^{1}\right)$, the global importance and, in some regions, dominance of the climatic water balance $\left(\mathrm{P}-\mathrm{E}_{\mathrm{p}}\right)$ as 
233 a driver of seasonal hydrologic buffering on land becomes evident. The global distribution of $234 \mathrm{SHB}_{\mathrm{cwb}}$ also 

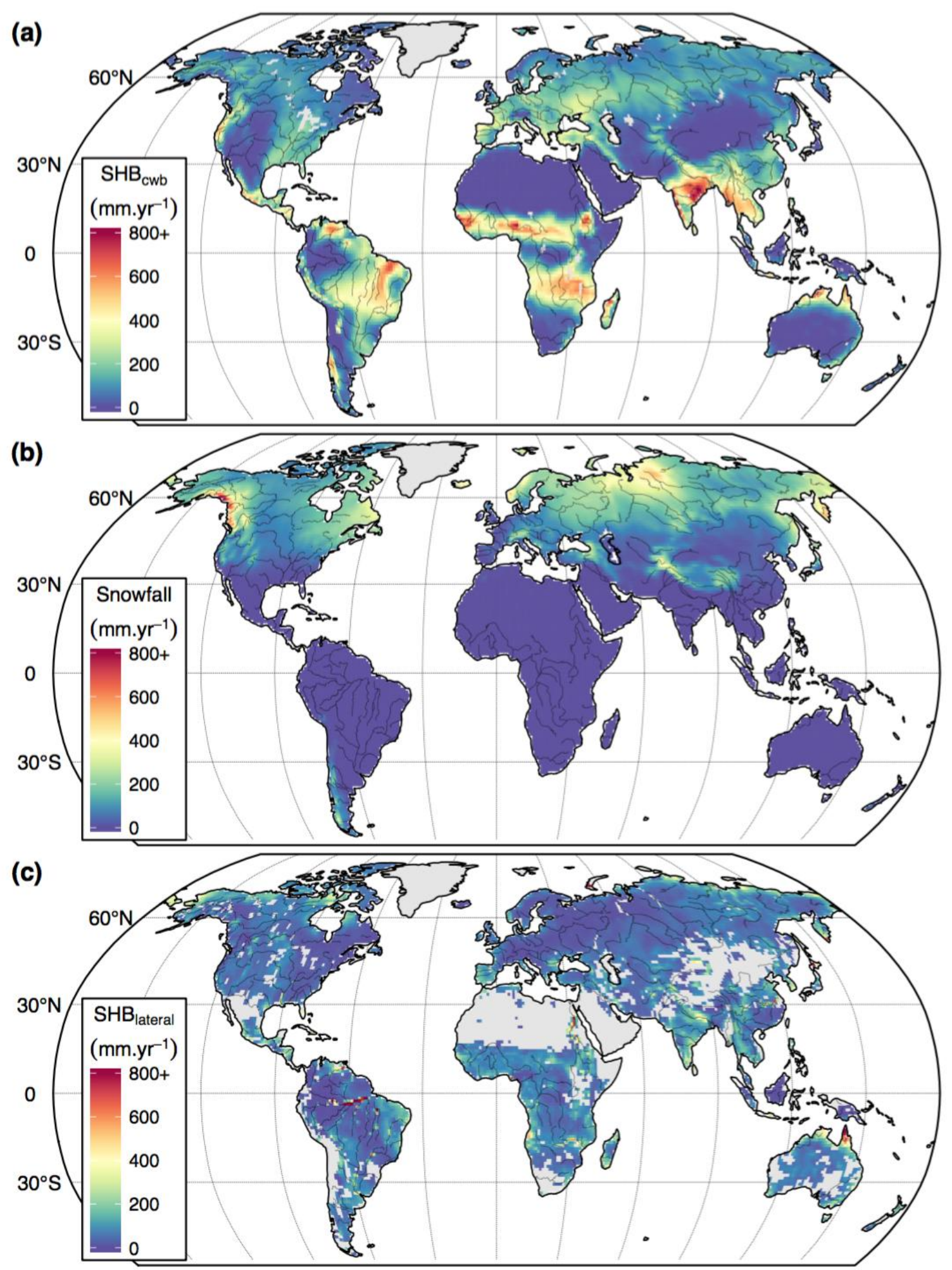

Figure 3. Continental distribution of the seasonal hydrologic buffer driven by (a) climatic water balance (precipitation - potential evaporation), (b) snow/ice storage and delayed release, and (c) lateral water transfer (inflow - outflow). 
236 echoes that of the root zone storage estimates derived at the global scale by [18], both in terms of 237 patterns and magnitude. This is a striking convergence considering that their associated 238 methodologies differed on several points: 1) the quantity reported in [18] is a storage capacity 239 while $\mathrm{SHB}_{\text {cwb }}$ is a flux (respectively analogous to $\mathrm{A}_{\mathrm{S}}$ and SHB), 2) in the water balance [18] uses 240 evaporation while we use potential evaporation (Eq. 4), 3) [18] takes into account water inputs 241 from irrigation in addition to $\mathrm{P}$, and 4) the only comparable input, $\mathrm{P}$, is obtained from 242 independent datasets (CRU TS3.22 [11] in the case of [18]).

243 The other important climatic driver that we explored was snow/ice storage and delayed melt, 244 which was shown to significantly decouple storage from runoff [19]. The magnitude and global 245 distribution of snow/ice storage is shown in Fig. 3b. Snow storage dominates the high 246 latitudes and altitudes, contributing to the total seasonal hydrologic buffering of regions where 247 it cannot be attributed to the $\mathrm{P}-\mathrm{E}_{\mathrm{p}}$ balance discussed earlier (e.g., Alaskan-Canadian Coastal 248 Range, and Western Siberian). In regions where at least 5\% of P is snow, 35\% of the SHB 249 variation across grid cells is explained by annual snowfall water depth amount (Fig. 4), 250 indicating a significant role played by snow and ice storage in driving seasonal hydrologic 251 buffering, whose area-weighted average water depth is $152 \mathrm{~mm} . \mathrm{yr}^{-1}$. 


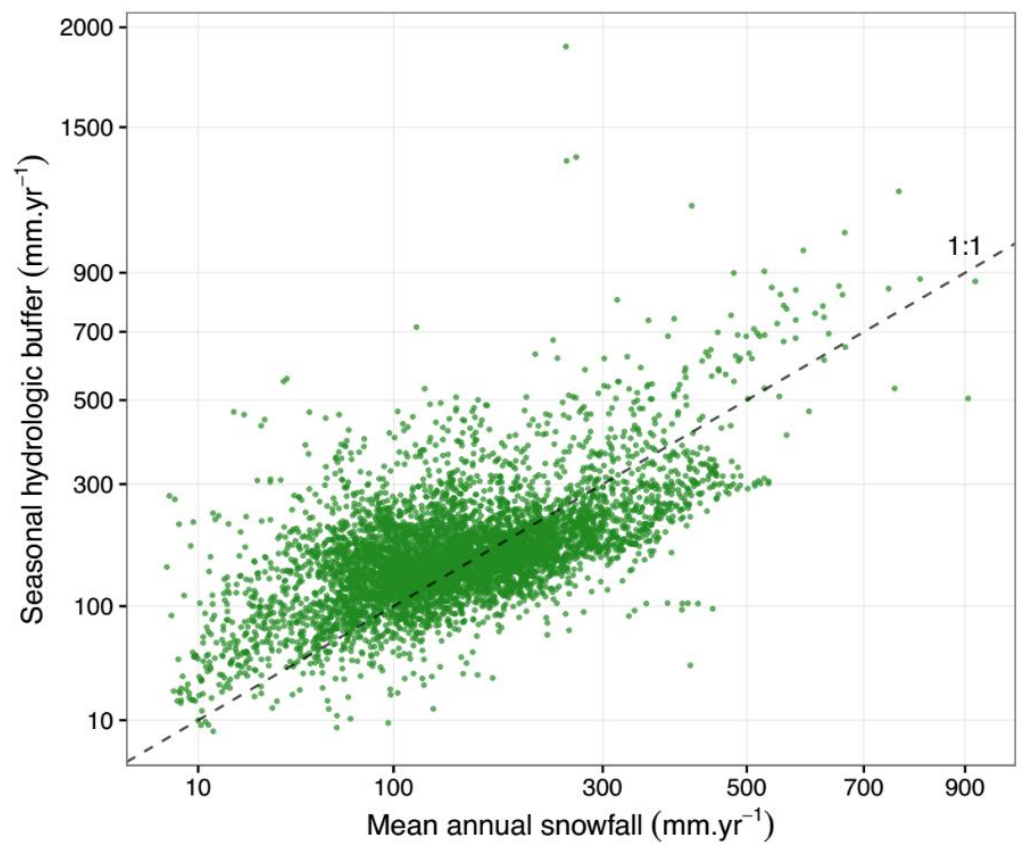

Figure 4. Vertically-integrated seasonal hydrologic buffer (SHB) versus mean annual snowfall, excluding locations with less than $5 \%$ of annual precipitation falling as snow and with low signal-to-noise ratio. Scales are non-linear for a better display of all data points.

\subsubsection{Terrain}

Long distance lateral fluxes are responsible for some seasonal hydrological buffering at specific locations. Water surpluses converging towards river/lake valleys and coastal lowlands, where flow is retarded until its eventual release to the ocean or its evaporation, are the dominant source of seasonal hydrological buffering at our scale of analysis (month to month, $1^{\circ} \times 1^{\circ}$ grid cells). This lateral convergence removes water in surplus months from large areas over the source region and concentrates it, typically in smaller areas, in downstream sink regions with examples coming from both relatively dry as well as wet basins [20,21]. Here, lateral transfer of water appears driven by the complex interplay of the myriad of terrain characteristics that shape

263 large basins (e.g., elevation, slope, soil and sediment thickness, faulting and tectonics, among others). Without globally consistent sediment thickness and effective porosity data, it is difficult to assess the subsurface portion of the land storage capacity in regulating total SHB. A surrogate

266 variable is the terrain slope, because steep slopes shed sediments and flat valleys accumulate 267 sediments resulting in deep sedimentary basins. However, the correlation between SHB and grid 
268 cell slope (mean or maximum from a 3" DEM, see Sect. 2.1) is statistically insignificant $(|\mathrm{r}|<$ 269 0.04). A main reason is that terrain-driven runoff is most pronounced at the hillslope scales (from 270 ridge to valley) which is too small, and the runoff time too short, to be resolved by the $1^{\circ} \times 1^{\circ}$ and 271 monthly scales considered here.

272 The continental distribution of the horizontal, seasonal hydrologic buffer defined in Eq. (7) is 273 shown in Fig. 3c. A comparison with Fig. 3a and 3b suggests that lateral transfer is far less 274 important than climatic factors in driving SHB, except for the lower reaches of large river 275 systems such as the Amazon $\left(>3,600 \mathrm{~mm} \cdot \mathrm{yr}^{-1}\right)$ and the Nile, funneling inflow from large 276 headwater basins into smaller storage areas. To describe the broad patterns of likely source, sink, 277 and passing-through regions engaged in this slow lateral transfer that is able to contribute to the 278 hydrologic buffering of continents, we calculated the correlation between storage change $(\Delta \mathrm{S})$ 279 and the net inflow $(\mathrm{Q}<0)$, and between $\Delta \mathrm{S}$ and net outflow $(\mathrm{Q}>0)$. A high correlation in the 280 former indicates that the grid cell is likely a sink, a high correlation in the latter indicates a likely 281 source, while a grid cell that is both sink and source suggests a likely passing-through location. 282 Figure 5 shows cells with correlation $>0.5$. Major source areas are located in boreal regions and 283 northern mountain ranges as well as selected areas of the per-humid tropics. Passing-through 284 areas are the most abundant and include boreal regions and large river valleys (Nile, Amazon, 285 Ganges, Indus, Zambezi, Mississippi). Sink areas are rarer and include a few deserts and 286 semiarid areas in all continents. 


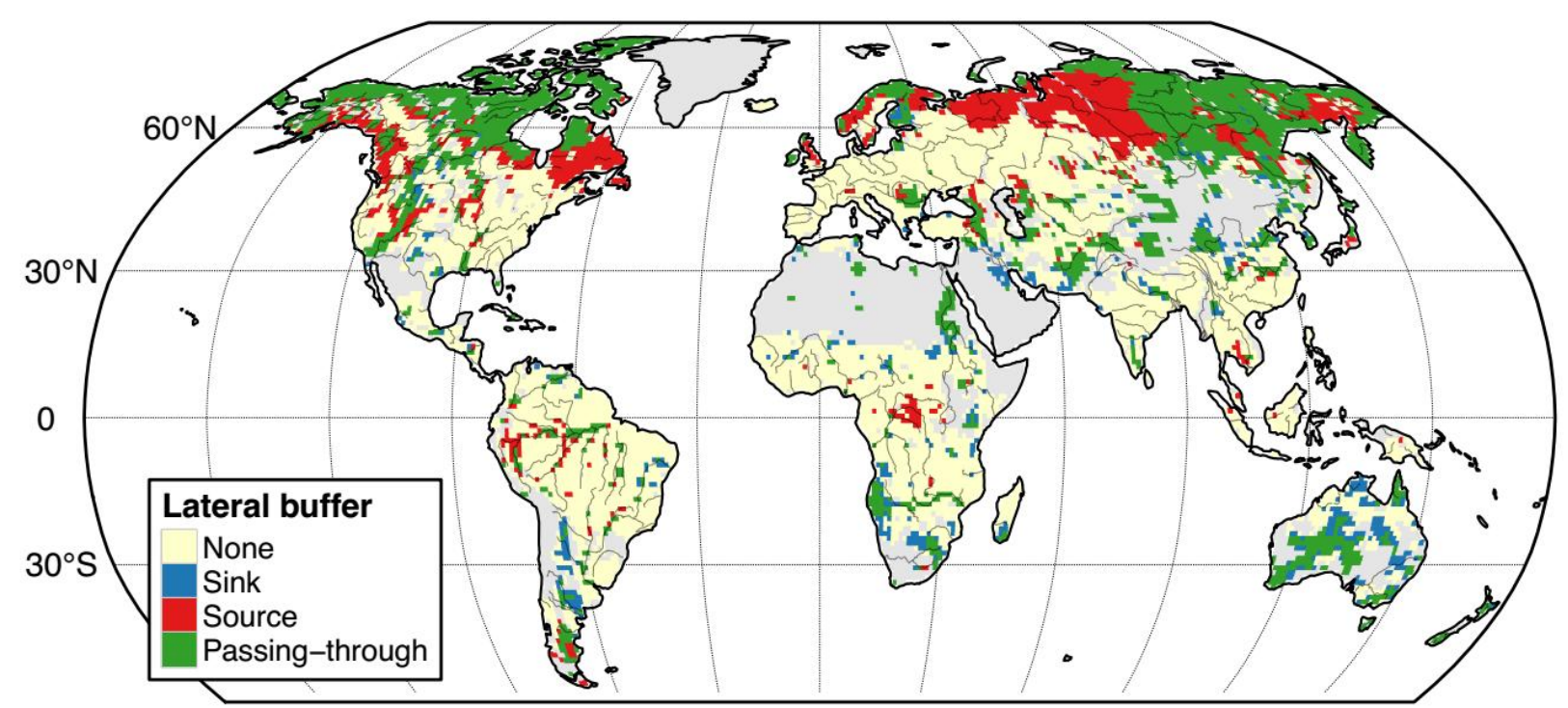

Figure 5. Locations where monthly changes in water storage are significantly correlated to monthly run-on (blue), monthly runoff (red) or both (green), excluding locations with low signalto-noise ratio (light grey) - It highlights where seasonal hydrologic storage is significantly controlled by lateral inflow ("buffered sink"), outflow ("buffered source"), or both ("buffered passing-through").

Finally, large man-made water reservoirs show their imprint at our coarse scale of analysis. Figure 6 plots the total SHB vs. the storage capacity of 10 largest reservoirs of the world (in terms of volume [22]), which shows a significant positive correlation, indicating that these reservoirs have a detectable contribution to the GRACE-observed seasonal storage change.

These analyses suggest that climate, through seasonal water surplus/deficit imbalances and 294 snow accumulation is the first-order driver of seasonal hydrologic buffering. Terrain-driven 295 lateral transfer influences only a small portion of the land surface (yet intensely in specific regions), and is only significant where/when the climatic surplus-deficit patterns align with terrain source-sink drainage directions. 


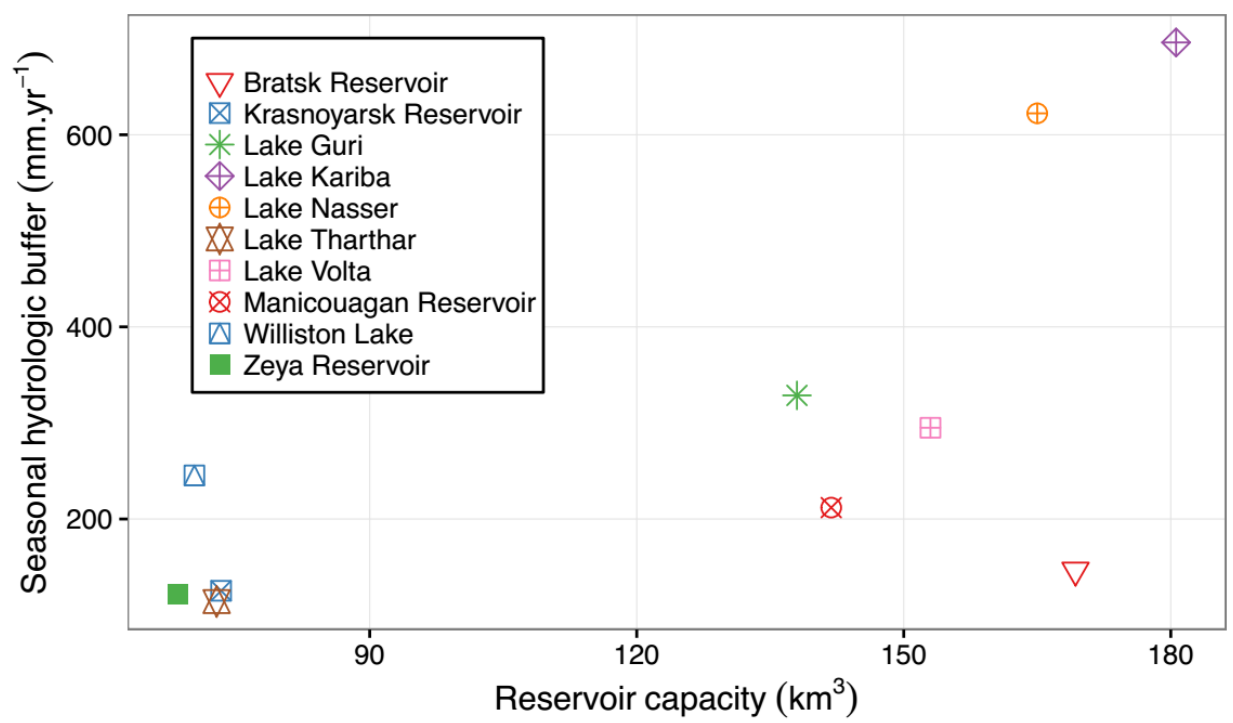

Figure 6. Vertically-integrated seasonal hydrologic buffer (SHB) against holding capacity, for the ten largest reservoir or artificial lakes.

\subsection{Benefits for ecosystems}

301

302

303

304

305

306

307

308

309

310

311

312

313

314

315

We identified the imprint of seasonal hydrological buffering on plant productivity (Question 3) through the examination of both evaporation (E) and vegetation greenness (EVI) patterns. The most direct hydrologic connection to plant productivity is vegetation water use, or evaporation (E), since on vegetated surfaces the latter is dominated by plant transpiration [23]. A direct evidence of vegetation benefiting from SHB is the occurrence of monthly $\mathrm{E}>$ monthly $\mathrm{P}$, where the deficit has to be met by temporal and/or spatial carry-over of past or neighbor's surplus, in addition to recent and local $\mathrm{P}$. This was already defined as subsidized $\mathrm{E}\left(\mathrm{E}_{\mathrm{s}}\right.$, subsidized from past or upslope surplus, Eq. (8)).

We first documented the fraction of the year in which $E_{s}$ takes place. Figure 7a plots the number of months per year where/when E>P, excluding grid cells with no vegetation. Except for areas that are wet and/or cool throughout the year, subsidized E occurs in at least 3 months of the year over most of the continental area, and in up to 9 months in strongly seasonal climates. The magnitude of the subsidized E over a year $\left(E_{\mathrm{s}}\right)$, is shown in Fig. 7b. While the continental areaweighted average is $190 \mathrm{~mm} \cdot \mathrm{yr}^{-1}$, significant $\mathrm{E}_{\mathrm{s}}\left(>400 \mathrm{~mm} \cdot \mathrm{yr}^{-1}\right)$ is found in the seasonal tropics where large wet-season rains are followed by a long dry-season, but plants continue to transpire 
316 in the year-round warm climate. Here, if it was not for the subsidy, dry-season productivity

317 would have been far more water-limited. Interestingly this large $\mathrm{E}_{\mathrm{s}}$ was noticed in both natural

318 forests (e.g. the Sudanian savanna in Africa) as well as in highly cultivated areas (e.g. Northern

319 India) (Fig. 7b). The actual water pool supporting $E_{\mathrm{s}}$ is typically assumed to be unsaturated soil

320 moisture and in order to achieve values beyond $600 \mathrm{~mm} \cdot \mathrm{yr}^{-1}$ that we observed in the regions

321 mentioned above, soils and roots reaching $>3 \mathrm{~m}$ of depth would be required [15]. This is likely

322 the case of natural woody ecosystems in the dry-seasonal subtropics but very unlikely in heavily

323 cultivated areas in which annual crops display much shallower roots. In these systems, however,

324 that saturated zone gets engaged into seasonal discharge and recharge cycles that provide active

325 buffering due to irrigation and/or crops directly tapping phreatic groundwater.

326 The relative contribution of recent ( $<1$ month) lateral inflow to subsidized E ( $\mathrm{E}_{\mathrm{ifl}}$, see Sect.

327 2.2) is shown in Fig. 7c. $\mathrm{E}_{\text {iflw }}$ is high in the plains of southern South America that are known to

328 be fed by Andean streams [21], in the inland deltas of the Okavango, the Chad and the Niger in

329 Africa, and the internal drainage basins of Central Asia including the Aral Sea, all large regions

330 nourished by rivers sourced in the more humid headwater basins. The coarse spatial resolution of

331 the study $\left(1^{\circ} \times 1^{\circ}\right.$ grids $)$ cannot articulate lateral convergence at hillslope and catchment scales,

332 and the temporal resolution (month to month, within a year) cannot capture the quicker (flash

333 flooding) or slower (groundwater transfer) lateral fluxes, yet some of the best known and most

334 salient features of lateral water subsidy of the world stand out in this simple analysis. In these

335 regions, societies and ecosystems depend on rain or snow that fall in remote regions up-gradient

336 for a large part of their water supply.

337 Finally, we correlate the subsidized E directly to the MODIS satellite observed vegetation 338 productivity, the enhanced vegetation index (EVI), over the months of $\mathrm{E}>\mathrm{P}$, as shown in 339 supplementary Fig. S3. High correlations are found in strongly seasonal dry or frozen climates 340 (climatic drivers) and the low basins adjacent to large mountain ranges (terrain drivers). 

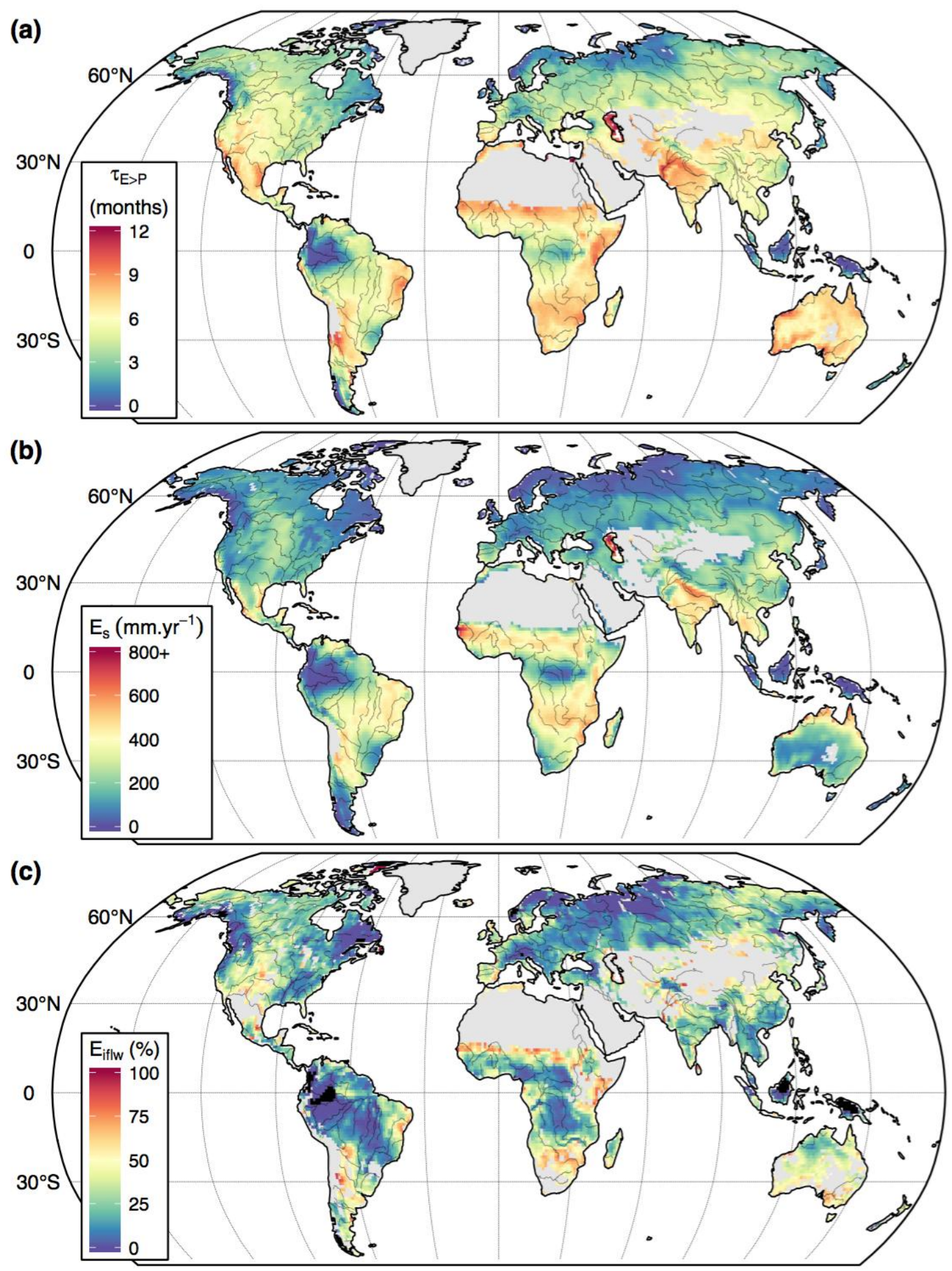

Figure 7. (a) Average number of months where evaporation (E) exceeds precipitation and (b) Mean annual subsidized $\mathrm{E}\left(\mathrm{E}_{\mathrm{S}}\right.$, i.e. E-P when $\left.\mathrm{E}>\mathrm{P}\right)$ during these deficit months, excluding locations without vegetation cover. (c) Proportion of $E_{S}$ attributed to recent $(<1$ month) lateral inputs $\left(\mathrm{E}_{\mathrm{ifl}}\right)$, excluding locations with null SET and with low signal-to-noise ratio. 


\section{Conclusions}

344 We examined storage and delayed release of monthly $\mathrm{P}$, focusing on global geographic patterns, climate and terrain drivers, and likely implications to terrestrial ecosystems. We found that seasonal hydrologic buffering (SHB) is primarily driven by climatic water imbalance, with SHB being most significant (>300 mm. $\mathrm{yr}^{-1}$ ) in tropical monsoonal climates followed by Mediterranean climates and strongly seasonal (dry or cold) climates, carrying over wet (or cold) season surplus to meet the following dry (or warm) season deficit (see Fig. 7b). Globally, about $25 \%$ of the annual P on land is held and released in later months.

Seasonal snow and ice accumulation is the second dominant driver of SHB, explaining the large storage and delayed release in the melt and growing seasons. Lateral water transfer through the rivers is the third dominant driver, but its importance depends on the climatic water balance: seasonal lateral transfer is only important where/when the higher elevation basins have large surplus, so that evaporative demand can be met by the subsidy from higher -and seasonally richer, e.g. [24]- neighbors. Large reservoirs, heavily regulated by humans, is the fourth detectable and regionally significant driver of SHB.

We find a direct evidence that SHB benefits land ecosystems and society, as seen in places and times where/when E exceeds local and recent P, which occurs frequently, at 3-9 months of the year (Fig. 7a), and widely, in all but per-humid and energy-limited regions of the world (Fig. 7b). This illustrates the paramount importance of land water storage. Without it, vegetation productivity, highest in the lower latitudes, would have been far more water-limited [25].

We note that, in addition to this direct impact of seasonal storage on $\mathrm{E}$, the positive feedbacks between $\mathrm{E}$ and $\mathrm{P}$ through continental precipitation recycling (e.g., [26]) may further amplify the impact of this storage, so that more E leads to a moister and cooler boundary layer (less drought stress), and sometimes more P locally or downwind, benefiting the ecosystems indirectly.

367 Neglected in this study are two important factors. The first is the role of vegetation as a regulator of land water storage: through high $\mathrm{E}$, it reduces the surplus of the wet month and accentuate the deficit. While we chose simplicity to tease out the first-order cause-effect relations, future works would benefit from more emerging observation-based global databases of 
371 root zone storage capacity [18]. Secondly, we neglect anthropogenic influences, except by large

372 reservoirs, in the seasonal storage and release, directly by irrigation and drainage, and indirectly

373 by changing vegetation types which alters rooting depth and E dynamics.

374 Nonetheless, these results provide insights into the future of the water cycle through 375 hydrologic buffering by continents under climate and land use changes. Although snow storage 376 can be shrunk by global warming, water balance may partially compensate it if the seasonal 377 decoupling of $\mathrm{E}$ and $\mathrm{P}$ increases, as expected if increases in dry-season length in the tropics-

378

379

380

381

382

383

384

385

386

387

388

389

390

391

392

393

394

395

396

397

398 subtropics take place $[27,28]$. On the other hand, effects of land use appear less important at the scale of this study, perhaps due to compensating effects (e.g. shorter crop roots in high $\mathrm{SHB}_{\mathrm{cwb}}$ regions are compensated by seasonal irrigation/recharge cycles that do not exist under the natural deep rooted vegetation). Far from illuminating future trends, our work provides a first contribution by showing where and how much continental hydrologic buffering influences the seasonal timing of the most relevant water fluxes for humans, i.e., those sustaining vegetation growth and river runoff.

\section{Acknowledgments}

This work has been supported by the Consejo Nacional de Investigaciones Científicas (CONICET) and the Agencia Nacional de Promoción Científica y Tecnológica of Argentina. GRACE land products are available at http://grace.jpl.nasa.gov, supported by the NASA MEaSUREs Program. ERAI/LAND precipitation and snowfall and ERA-Interim evaporation datasets are available from the Web Applications Server of the European Center for Medium Range Weather Forecasting (ECMWF), respectively at http://apps.ecmwf.int/datasets/data/interim-land/ and http://apps.ecmwf.int/datasets/data/interimfull-daily/, while potential evaporation of CRU TS3.23 can be retrieved from http://www.cru.uea.ac.uk/cru/data/hrg/cru_ts_3.23/. The SRTM data can be accessed through the Long Term Archive portal of USGS (https://ta.cr.usgs.gov/SRTM), the MODIS data was obtained using the REVERB data portal (http://reverb.echo.nasa.gov), and the ESA-CCI land cover data and the corresponding sub-setting/re-projecting/re-sampling tools are available on 
http://www.esa-landcover-cci.org. We thank two anonymous referees whose comments and

suggestions significantly improved the analysis and the presentation of the material in this paper.

401

402

403

404

405

406

407

408

409

410

411

412

413

414

415

416

417

418

419

420

421

422

423

424

425

426

427

428

429

430

431

432

433

434

435

436

437

438

439

440

441

\section{References}

[1] L. Marchi, M. Borga, E. Preciso, E. Gaume, Characterisation of selected extreme flash floods in Europe and implications for flood risk management, J. Hydrol. 394 (2010) 118-133. doi:10.1016/j.jhydrol.2010.07.017.

[2] K. Maher, C.P. Chamberlain, Hydrologic regulation of chemical weathering and the geologic carbon cycle, Science. 343 (2014) 1502-1504. doi:10.1126/science.1250770.

[3] C.W. Thornthwaite, The moisture-factor in climate, Eos Trans. Am. Geophys. Union. 27 (1946) 41-48.

[4] B.D. Tapley, GRACE Measurements of Mass Variability in the Earth System, Science. 305 (2004) 503-505. doi:10.1126/science.1099192.

[5] S. Swenson, J. Wahr, Post-processing removal of correlated errors in GRACE data, Geophys. Res. Lett. 33 (2006) L08402. doi:10.1029/2005GL025285.

[6] F.W. Landerer, S.C. Swenson, Accuracy of scaled GRACE terrestrial water storage estimates, Water Resour. Res. 48 (2012) W04531. doi:10.1029/2011WR011453.

[7] C. Sakumura, S. Bettadpur, S. Bruinsma, Ensemble prediction and intercomparison analysis of GRACE time-variable gravity field models, Geophys. Res. Lett. 41 (2014) 1389-1397. doi:10.1002/2013GL058632.

[8] G. Balsamo, C. Albergel, A. Beljaars, S. Boussetta, E. Brun, H. Cloke, D. Dee, E. Dutra, J. Muñoz-Sabater, F. Pappenberger, others, ERA-Interim/Land: a global land surface reanalysis data set, Hydrol. Earth Syst. Sci. 19 (2015) 389-407. doi:10.5194/hess-19-3892015.

[9] D.P. Dee, S.M. Uppala, A.J. Simmons, P. Berrisford, P. Poli, S. Kobayashi, U. Andrae, M.A. Balmaseda, G. Balsamo, P. Bauer, P. Bechtold, A.C.M. Beljaars, L. van de Berg, J. Bidlot, N. Bormann, C. Delsol, R. Dragani, M. Fuentes, A.J. Geer, L. Haimberger, S.B. Healy, H. Hersbach, E.V. Hólm, L. Isaksen, P. Kållberg, M. Köhler, M. Matricardi, A.P. McNally, B.M. Monge-Sanz, J.-J. Morcrette, B.-K. Park, C. Peubey, P. de Rosnay, C. Tavolato, J.-N. Thépaut, F. Vitart, The ERA-Interim reanalysis: configuration and performance of the data assimilation system, Q. J. R. Meteorol. Soc. 137 (2011) 553-597. doi:10.1002/qj.828.

[10] B. Mueller, S.I. Seneviratne, Systematic land climate and evapotranspiration biases in CMIP5 simulations, Geophys. Res. Lett. 41 (2014) 128-134. doi:10.1002/2013GL058055.

[11] I. Harris, P.D. Jones, T.J. Osborn, D.H. Lister, Updated high-resolution grids of monthly climatic observations-the CRU TS3. 10 Dataset, Int. J. Climatol. 34 (2014) 623-642. doi:10.1002/joc.3711.

[12] R. Solano, K. Didan, A. Jacobson, A. Huete, MODIS vegetation indices (MOD13) C5 user's guide, Tucson Univ. Ariz. (2010).

[13] T.G. Farr, P.A. Rosen, E. Caro, R. Crippen, R. Duren, S. Hensley, M. Kobrick, M. Paller, E. Rodriguez, L. Roth, others, The shuttle radar topography mission, Rev. Geophys. 45 (2007) RG2004. doi:10.1029/2005RG000183.

[14] B. Poulter, N. MacBean, A. Hartley, I. Khlystova, O. Arino, R. Betts, S. Bontemps, M. Boettcher, C. Brockmann, P. Defourny, others, Plant functional type classification for earth 
442

443

444

445

446

447

448

449

450

451

452

453

454

455

456

457

458

459

460

461

462

463

464

465

466

467

468

469

470

471

472

473

474

475

476

477

478

479

480

481

482

483

484

485 system models: results from the European Space Agency's Land Cover Climate Change Initiative, Geosci. Model Dev. 8 (2015) 2315-2328. doi:10.5194/gmd-8-2315-2015.

[15] A. Kleidon, M. Heimann, A method of determining rooting depth from a terrestrial biosphere model and its impacts on the global water and carbon cycle, Glob. Change Biol. 4 (1998) 275-286. doi:10.1046/j.1365-2486.1998.00152.x.

[16] M. Rodell, Basin scale estimates of evapotranspiration using GRACE and other observations, Geophys. Res. Lett. 31 (2004) L20504. doi:10.1029/2004GL020873.

[17] M. Kottek, J. Grieser, C. Beck, B. Rudolf, F. Rubel, World map of the Köppen-Geiger climate classification updated, Meteorol. Z. 15 (2006) 259-263. doi:10.1127/09412948/2006/0130.

[18] L. Wang-Erlandsson, W.G. Bastiaanssen, H. Gao, J. Jägermeyr, G.B. Senay, A.I. van Dijk, J.P. Guerschman, P.W. Keys, L.J. Gordon, H.H. Savenije, Global root zone storage capacity from satellite-based evaporation, Hydrol Earth Syst Sci. 20 (2016) 1459-1481. doi:10.5194/hess-20-1459-2016.

[19] J. Riegger, M.J. Tourian, Characterization of runoff-storage relationships by satellite gravimetry and remote sensing, Water Resour. Res. 50 (2014) 3444-3466. doi:10.1002/2013WR013847.

[20] H. Kim, P.J.-F. Yeh, T. Oki, S. Kanae, Role of rivers in the seasonal variations of terrestrial water storage over global basins, Geophys. Res. Lett. 36 (2009). doi:10.1029/2009GL039006.

[21] E.G. Jobbágy, M.D. Nosetto, P.E. Villagra, R.B. Jackson, Water subsidies from mountains to deserts: their role in sustaining groundwater-fed oases in a sandy landscape, Ecol. Appl. 21 (2011) 678-694. doi:10.1890/09-1427.1.

[22] B.F. Chao, Y.H. Wu, Y.S. Li, Impact of artificial reservoir water impoundment on global sea level, Science. 320 (2008) 212-214. doi:10.1126/science.1154580.

[23] W.H. Schlesinger, S. Jasechko, Transpiration in the global water cycle, Agric. For. Meteorol. 189 (2014) 115-117. doi:10.1126/science.1154580.

[24] S.-C. Han, H. Kim, I.-Y. Yeo, P. Yeh, T. Oki, K.-W. Seo, D. Alsdorf, S.B. Luthcke, Dynamics of surface water storage in the Amazon inferred from measurements of intersatellite distance change, Geophys. Res. Lett. 36 (2009) L09403. doi:10.1029/2009GL037910.

[25] K. Guan, M. Pan, H. Li, A. Wolf, J. Wu, D. Medvigy, K.K. Caylor, J. Sheffield, E.F. Wood, Y. Malhi, others, Photosynthetic seasonality of global tropical forests constrained by hydroclimate, Nat. Geosci. 8 (2015) 284-289. doi:10.1038/ngeo2382.

[26] R.J. van der Ent, H.H.G. Savenije, B. Schaefli, S.C. Steele-Dunne, Origin and fate of atmospheric moisture over continents, Water Resour. Res. 46 (2010) W09525. doi:10.1029/2010WR009127.

[27] N.S. Diffenbaugh, F. Giorgi, Climate change hotspots in the CMIP5 global climate model ensemble, Clim. Change. 114 (2012) 813-822. doi:10.1007/s10584-012-0570-x.

[28] R. Fu, L. Yin, W. Li, P.A. Arias, R.E. Dickinson, L. Huang, S. Chakraborty, K. Fernandes, B. Liebmann, R. Fisher, others, Increased dry-season length over southern Amazonia in recent decades and its implication for future climate projection, Proc. Natl. Acad. Sci. 110 (2013) 18110-18115. doi:10.1073/pnas.1302584110. 